\title{
Cultural consumption and the myth of 'life-style'
}

\author{
Neil Maycroft \\ History of Art \& Material Culture \\ Lincoln School of Art \& Design \\ University of Lincoln \\ e-mail: nmaycroft@lincoln.ac.uk
}

This paper was originally published as 'Cultural consumption and the myth of "life-style", in Capital \& Class: Special Issue on Cultural Production, Consumption and Resistance, No 84, October 2004 . 


\begin{abstract}
The concept of 'life-style' seems to have been thoroughly naturalised, both academically and in common parlance. There is little critical interrogation of what 'life-style' involves, beyond its connection to cultural and aesthetic aspects of consumption. What are the implications of accepting this culturalised description of consumption and its shorthand designation, 'lifestyle'? This polemical paper interrogates both the linguistic and conceptual challenges associated with the term, and argues that it acts to efface and erase important social differences of wealth, opportunity, class, gender and ethnicity, as well as obscuring global and historical inequalities.
\end{abstract}

\title{
Introduction
}

Imagine if critical social theorists littered their conversations and writings with terms like 'advertorial', or 'infotainment', in an unselfconscious or unexamined manner. The use of such terms tends to make us wince, because they are easily seen as the jargon of the advertising industries, and as neologisms that blur the boundaries between distinct activities or concepts. They can be read as terms that append commercial connotations to realms that have usually been widely defended against commercial pressures: editorials and information. Yet while many commentators object to the commodification of these activities, they often use the term 'life-style' in a less than critical way. A clear example of this is in contemporary discourses around the creative industries, which routinely refer to the concept of 'lifestyle', as it is often written, and easily conflate it with notions of economic and cultural development, 'quality of life', social inclusion and cultural diversity. Central to this conflation is the location of lifestyle firmly within the nexus of consumerism, and the relegation of culture to the consumption of the products, services and experiences that the creative industries supply. Moreover, some critics of the concepts that lie behind the term life-style use the term themselves in a neutral or positive manner.Yet I contend that this term belongs with the other neologisms mentioned above. It is a term that denotes the attempted commodification of life in general, and the handing over of living itself to the market (Fromm, 1976), such that the consumption of the products, services and experiences purveyed by the creative industries are presented as being synonymous with the 'consumption' of life itself.The chief 
problem with life-style, and the explanation of consumption upon which it rests, is that it overplays the importance of consumption and consumerism in people's lives. Moreover, it exaggerates the aesthetic and symbolic pleasures of consumption, and consequently downplays both the other pleasures that are derived from consumption, and the more material concerns that are a central aspect of consumption and consumerism. This over-emphasis on consumption and its associated symbolic pleasures forms part of what Lodziak (2000, 2002) has termed the 'ideology of consumerism', and this paper is heavily indebted to that particular critique of the 'myth of consumerism'. From such a perspective, life-style can be taken as something different to a life: almost as something undertaken, instead of an autonomous, self-directed attempt to live a full and rounded life. It acts as a consumerist carapace, resisting and defending against the possibilities of a life lived away from consumerism. Against this view, my contention is that no one has a life-style: they live lives. ${ }^{1}$

\section{Life-style: The word itself}

According to the Oxford English Dictionary, the term was originally used by Alfred Adler in 1929, to denote a person's basic character as established early in childhood, and which governs his or her reactions and behaviour. Until the 1970s, the term retained this psychological connotation, and was almost always rendered as 'life-style'. As a result of market research surveys carried out in the USA, from the 1970s onwards the term became inextricably tied to consumption practices, and took on the familiar form 'lifestyle'. I continue to hyphenate the term here, since the loss of the hyphen draws the two terms into one, and represents a grammatical device through which they are naturalised and stripped of their critical social content. As Marcuse argued, 'The syntax of abridgement proclaims the reconciliation of opposites by welding them together in a firm and familiar structure[;] . . commercialization joins formerly antagonistic spheres of life, and this union expresses itself in the smooth linguistic conjunction of conflicting parts of speech' (Marcuse, 1964: 89). Marcuse criticised the preponderance of abridgement and the

\footnotetext{
${ }^{1}$ However, a common response to the statement that one lives a life, rather than having a life-style, is one of suspicion at the speaker's piety, even though many of the same people may use the term 'life-style' about themselves and others with little consistency or certitude as to its meaning.
} 
hyphenation of terms; however, 'lifestyle' goes beyond this into unabridged, non-hyphenated 'unity'. 'The effect is a magical and hypnotic one-the projection of images which convey irresistible unity, harmony of contradictions (Marcuse, 1964: 93).

Although many definitions of the term are to be found in literature on consumption, and as components of the promotional culture of capitalism itself, a generic definition of the term can be arrived at: a reflexive, biographical project of identity-formation and self-presentation, based upon the consumption of the symbolic dimensions of consumer commodities, particularly cultural products, services and experiences. Some kind of 'project' or strategy is implied or explicitly claimed; a scheme that makes sense of consumer choice, reduces the anxiety that flows from having to make such choices, and provides a consistent framework within which consumption decisions are made, such that there is a consonance between the objects, services or experiences chosen and consumed.

The freely chosen symbolic and aesthetic pleasures deemed to be central to consumption practices are the cornerstone of life-style activities. There is a growing body of literature that questions the plausibility, processes and logic of this particular explanation of consumption and 'consumerism' (Warde, 1994; Bowring, 1999; Lodziak, 2000, 2002).While I would endorse these critiques of consumerism, reiterating them is not my main concern. Rather, I want to focus on the concept, content and use of the term 'life-style' itself with the implication that, even if we accept the model of consumer behaviour on which it is based, the term itself is still open to severe critical inquiry.That is why it is curious that writers who reject the model of consumerism on which the term 'life-style' rests still, nevertheless, often use the term in an uncritical and unexamined manner. Some initial and obvious questions can thus be posed: what are the points of demarcation that distinguish life-style from life? What turns a life into a life-style; what turns a life-style into a mere life (and the 'mere' is deliberate, since life-style is increasingly lauded as the mode of living). What exactly is being styled, and in what ways? What is the relationship between 'life' and 'style'? How does a life-style differ from a life? Who has a life-style; who does not; and so on. ${ }^{2}$

\footnotetext{
${ }^{2}$ Many accounts describe an individual's relationship to lifestyle as being one of ownership: one 'has' a life-style. This brings to mind Erich Fromm's demarcation of 'having' and 'being' modes of life; it could be argued that life-style, with its possessive and consumerist orientation, belongs to the 'having' mode, rather than to the process-oriented
} 


\section{Life-style: Examples of use}

There follows just a small selection of examples, which demonstrates the range and sometimes absurd use of the term life-style:

- A building development proclaiming 'city life-style' apartments. What is a city life-style, does everyone who lives in a city share such a designation, a common mode of living, a common mode of consuming even? Even more strangely:

- 'Enjoy life-style living': a bizarre invitation, declaration or instruction found on another advertising board for new apartments. No adjective is even included here, only the proclamation of life-style itself!

The term is also increasingly projected back historically, onto social formations qualitatively different from our own:

- In a book titled A Centenary History of Nottingham, published in 1997, leisure and recreation activities are referred to as forming part of a 'lifestyle' in late eighteenth and early nineteenth century England.

- In the first episode of the BBC television series A History of Britain, the narrator described the 'life-style' of the Romans in Britain.

The trans-historical use of the term should sound alarm bells, but it is also extended to non-human nature:

- In the BBC programme Wildlife on One, the narrator referred to the 'life-style' of hyenas.

- On the BBC's Animal Hospital, a vet opined that a tortured, neglected and starved cat had not had a very good 'lifestyle.

Such absurd and amusing usage might, justly, lead to a call for more rigorous and consistent use of the term. This rather begs the question of what specific content should inform its rigorous and consistent usage, but

'being' mode (Fromm, 1976). 
nevertheless it is an understandable objection to such silly examples. However, I want to take the backwards historical projection of the term seriously, in order to interrogate some of the logic upon which it rests. If life-style is simply about choices in consumption then it is a trans-historical category, since all human societies have had choices about what to eat, wear, build, experience symbolically, etc., albeit within varying physical, technical and cultural limits.

Still, the principle remains: life-style is simply about choosing this and not that, for whatever reasons. If so, it is a pretty meaningless term, shorn of the specificity of content it claims. However, if we project life-style back into history while preserving its current meaning, we are insinuating that the production, exchange and consumption of material use values, symbols and experiences required for the satisfaction of needs proceeded in the past in the same way as it does today. That is, we run the risk of either naturalising capitalism as a trans-historical social formation, or we run the equally serious risk of obscuring the specificity of capitalism as the political-cultural economy of contemporary society, and of other modes of production as underpinning other social formations. This projecting backwards of life-style also carries with it some decontextualised notions of taste, culture, image and style as motivations for consumption.

There are already many good reasons to reject such motivations in current consumption practices, but to project these sensibilities backwards is surely problematic. The proponents of the 'ideology of consumerism' themselves claim such motivations for consumption to be historically novel, and yet unproblematically project life-style backwards onto history. If we grant that the extension of the term 'lifestyle' backwards is shorn of its contemporary specificity, we are again left with an empty term, and may as well abandon it in favour of words such as 'life' or 'consumption', 'needs' and 'satisfaction, etc. If cats have life-styles, then the term obviously becomes meaningless unless used as a synonym for existence in general, or unless one wants to hold to some weird, anthropomorphic stance in which cats 'consume' cultural commodities, and consume them in a symbolic manner. ${ }^{3}$ If life-styles are

\footnotetext{
${ }^{3}$ Perhaps not so absurd. IAMS cat food is currently being promoted as forming 'part of a healthy "lifestyle" for cats. This represents a heightening, on the part of advertisers, of the anthropomorphism of domestic pets, such that their owners might be persuaded to buy certain products for them by regarding them as having human preferences and motivations for consumption. For example, one brand of dog food is currently being
} 
unique to humans in contemporary capitalist societies, and we reject all ideas linking the term to hyenas, cats or Romans, then the other roads of criticism mentioned earlier open up: namely, the fetishisation of consumption and the elevation of cultural consumption to such a high status that it lays a shell over the human subject. So let us now place the trans-historical seepage of the term life-style to one side, and instead concentrate on its contemporary usage.

\section{Work and life-style}

In most of the literature concerning life-style, a clear demarcation is made between the world of paid labour as a non-life-style realm, and the world outside of work as the one in which expressive life-style activities take place (see Chaney, 1996). Consider the following, seemingly innocuous, quotation: 'Abuse of the work-force, either through its being rendered redundant or through its being brutalised, actively prevents many of us from enjoying an acceptable lifestyle.' (Greenhalgh, 1997: 113).

This appears to be a rather obvious statement, and one that follows much of the orthodoxy concerning life-style. The implication is that lack of work and poor quality employment reduce life chances and opportunities away from work (in the arena of life-style activities). At first sight, this would appear to be unobjectionable. However, if the assertion is that unemployment or brutalised employment tend to make the rest of one's life disagreeable, then why do we need the term life-style? Why frame such a situation in this way? Many people in brutalised work or without employment cogently articulate the reality of lost and denied opportunities away from work, without invoking such a split. Life is harsh in all its aspects, and is merely harsh in different ways in work and away from work. If brutality and despair, euphoria and happiness are aspects of all activities, then there is no justification for not applying the term life-style to activities associated with work (or lack of it). But this is precisely one of the demarcations that many commentators insist upon. Either all activities form part of our life-style, in which case the word lacks the specificity that is claimed for it, or everything is part of our lives, in which case we do not need the term life-style at all. There is a little more to be said here, however. Improving one's life-style by improving one's

advertised on television as having the flavour of 'chicken provençal. 
working conditions appears to make sense, since it is about increasing one's wage, one's job protection, one's safety, etc. But aiming to improve one's overall life by improving one's life-style, that is, one's ability to consume and consume symbolically, is more problematic. The dynamic is not reciprocal. The compensations, pleasures and reforms of the sphere of consumption do not flow back into the world of work in the same manner that improvements in work may flow out into the sphere of consumption.

For example, we are generally both consuming more and working more; indeed, we have to work more in order to enable further necessary consumption, or to enable 'more' life-style. We buy more products, services and experiences, but our work becomes increasingly burdensome, injurious to health and less satisfying. We work more and more for less and less life-style.We could even argue, against most convenient definitions, that life-style does flow back into work. After all, people have to make choices in relation to the presentation of the self at work: clothing, transport, food eaten at work, and so on. Some kind of overall consistency or project may be cultivated in this regard. This might be consonant with a person's actual consumption preferences or it might, of course, be an instrumental construction intended to make a particular impression at work. People make choices according to the resources at their disposal, and in accordance with their perception that such choices will be part of successful courses of action. They do this at work and away from work, so just why do these actions away from work deserve the specificity and enclosing that life-style implies? The unemployed are significant here. The unemployed, and the very many low waged workers, may aspire to both increased working hours (that, is a job) in order to secure the money needed for consumption, and increased incomes, since theirs are often too low to satisfy their basic needs in the market place. That is, both their non-life-style realm and their life-styles are unacceptable. Again, we are faced with the problem of trying to demarcate the two. Indeed, one could pursue some of the implications of this, and argue that the unemployed do not have life-styles at all. First, they do not have the means to engage in the levels and type of consumption associated with life-style activities. Second, since they have no work realm they have nothing to contrast their potential life-style activities against. They become simply a mass of undefined, undifferentiated, un-acculturated others, who fail to fall into the facile and superficial categories of the life-style proponents. In this sense, the term 'life-style' works to reinforce ruling class ideologies about the nature of the poor and the unem- 
ployed (Bauman, 1998). The poor and the unemployed have little practical choice but to aspire to both more work and more consumption; but that does not prove that they have some overriding desire to fashion their lives so that they are driven solely through choices in consumption, especially symbolic ones (Bowring, 1999).

\section{Lifestyle and consumption}

The promotional industries of capitalism generate characteristic representations of consumers based on market research (which we have many reasons to believe are deeply flawed: see Campbell, 1995). These representations appear in advertisements and life-style guides, and spread throughout consumer culture in general. Many commentators on consumer culture seem to take these promotional representations for portraits of real human behaviour.

These model consumers become the object of analytical attention, and their consumption-driven behaviour, identities and world-view are taken for authentic behaviour and sensibility in the real world. Indeed, most of their 'life chances' are represented as being dependent on choices in consumption. While many academics would not recognise these portrayals as applying to themselves or their friends, family or colleagues, they seem able to accept them as roughly accurate depictions of other people and of their motivations to consume. Life-style fits into this ideology well: first, consumption is reduced to its cultural and symbolic dimension, and second, life-style acts to further condense this partial account into the core and essence of contemporary existence, 'I shop therefore I am'.

However, do two people who choose to drive the same particular brand of automobile necessarily have anything more in common than their consumption and use of this specific commodity? The concept of life-style suggests that they do; that they share much in common; that they have similar or significantly overlapping 'projects of consumption' or life-styles. However, there seems to be little evidence to suggest that a shared fondness for particular automobile brands indicates a similarly mutual fondness for specific foodstuffs, holiday destinations or types of music.To imagine that such congruence is identifiable is surely either guesswork, fanciful wish-fulfilment, or an acceptance of capitalism's promotional culture of superficial categorisation of people on the basis of their insignificant preferences. Even if two 
people were to share all of the above preferences, it cannot be inferred from this that other, more significant aspects of their lives are similar enough to classify them as sharing a common life-style. What about occupation, political beliefs, sexual inclination, and so on? Can these really be read off the life-style checklist through the lens of a common penchant for a particular foodstuff? If we follow the logic of this kind of critique, we end up by having to acknowledge that all individuals will both make choices in consumption that are shared with many other people, and other choices that are not. No two people make identical choices and no two people, therefore, share identical life-styles.

People's cultural lives are over-determined, and not subject to the linear logic implied by marketing categorisations. Life-style emphasises cultural similarities, but has little significant to say about lived cultural differences, especially those that do not involve consumption. Life-style is invoked to denote a common collective sensibility, and the result is the classification of human behaviour according to consumption patterns, organised into a series of life-style categories.

\section{Life-styles of the rich and famous}

We are often informed that we live in a society obsessed with fame and celebrity gossip, and there are plenty of invitations to see how the rich, famous and successful apparently live their lives. However, the very term 'life-styles of the rich and famous' tends to neutralise the social relations leading to such social differentiation.

Rich people's life-styles are somehow judged as something that we could have had, given more fortunate opportunities, harder work, more commitment. The reality of capitalist social relations is lost in such a designation. These life-styles come about on the basis of the greater life chances afforded from the operations of capitalism. Appropriations of wealth, both direct and indirect, the extraction of surplus value, and (cultural) exploitation lie behind the differential distribution of life chances. To conceptualise the life-styles of the rich and famous as manifestations of social inequality, exploitation and greed is to run the risk of an accusation of a politics of envy, which the meritocratic ideology of consumerism does not tolerate. However, the term 'life-style' does contribute to the ideological obfuscation of an imputed 
cultural 'meritocracy', since famous life-styles are presented as consumerist dreams that are well deserved by those celebrities who enjoy them.

\section{Ethnic life-styles}

Ethnic life-styles, what could these be, apart from some vague intimation that some groups live differently from the 'mainstream'? If one eats traditional food, is this part of a way of life or of an ethnic life-style? Does eating a fastfood burger break with an ethnic life-style and represent part of a Western life-style? On what basis can a distinction be made? Similarly, if one chooses to wear traditional dress on some occasions, is this part of a way of life or of a life-style? Is the wearing of Western clothes a life-style activity and not part of a way of life? The facile term 'lifestyle' seems to celebrate such splitting of the individual into an array of consumerist components.

While terms such as 'ethnic' or 'traditional' life-style may tend to suggest an equivalence between Western models based on consumption, and other modes of living with a content derived more from traditional, religious or cultural factors, they can also be invoked to suggest something suspicious about the ways in which others live. What of such ethnic life-styles as they are experienced in a global context? What about the global poor, for example?

Designating the lives of those losers in the global capitalist economy as a life-style is immediately objectionable but, moreover, to use the term in this way also carries the danger of projecting its underlying assumptions in inappropriate ways. It implies that the unfortunate have somehow made a choice to live in this way; that they are making a market decision and expressing a cultural preference.

This view carries the pre-established assumption that the market is always an opportunity, rather than a constraint or imperative. Yet such people may experience the global market mostly as imperative, rather than as opportunity. In this sense the term life-style falls apart, or appears in its most restricted sense: aspects of life secured via the opportunity to engage in market-provided consumption. Many of these unfortunate people experience the global market as something that has impelled them to turn their backs on other forms of social and economic organisation in order to secure the necessities of life. 
Non-market provision for the satisfaction of needs is often destroyed or undermined by the power of the global market. People may engage in lifestyle type consumption activities, but these may have been imposed through the destruction of alternatives. To put it crudely, if there's only Coca-Cola to drink, then drinking Coca-Cola should not be interpreted as a life-style consumption choice.

\section{Unhealthy life-styles}

The talk of unhealthy life-styles is equally problematic. Activities that lead to an increased risk of cancer, heart disease, etc., are not life-style activities. They represent potential threats to the healthy continuation of life itself. To regard them as life-style illnesses denigrates the centrality of the body and corporeality. The notion of life-style illness also throws an enormous amount of responsibility onto individuals.

Not having access to the mixture of resources required in order to buy good quality, nutritious food is not a life-style option; not having access to cheap or free public sports and leisure facilities is not a life-style choice; having inadequate time to recover from the mental and physical stresses of work is not a life-style issue. Being treated with disregard and as an anonymous statistic within a failing health service is not a life-style choice.

The heavily promoted pleasures of consumption seem scant compensation for these life-chance conditions. Moreover, casting responsibility onto the individual enables the judging of these unhealthy life-styles against a range of acceptable and healthy alternatives. To dissent even mildly in respect of one's dietary, exercise and narcotic-related activities is seen as indicative of an unhealthy life-style, and of an underlying, questionable attitude.

\section{Digital life-styles}

Let us consider those designations of life-style whereby the consumption of a certain range of goods, services or experiences gives rise to generic prefixes: 'surfing' life-styles, 'angling' life-styles, and the like. The example considered here is that of 'digital life-styles'. A digital life-style is one in which it is suggested that a significant proportion of a person's time, a central preoccupation of their work or leisure activities, or the general cultivation of an 
interest, flows from the consumption of 'digital' goods, services and experiences. These may include the frequent use of a personal computer, a digital camera, a mobile telephone; and regular access to the internet, email and so on. It would follow from this that any two people who shared these interests, or who made the consumption of these things a significant part of their lives, would share a digital life-style. As an academic I could be deemed to have a digital life-style, since I use the above mentioned goods and services as a central part of my teaching, research and leisure activities.

Beyond the consumption of these goods and services, however, just how much does this indicate that I have, in common with another person, a digital life-style? A consideration of two designations of notions of digital life-styles should suffice to illustrate the problems inherent in the use of the term in this way. One of the means by which the British National Party was able to achieve and coordinate its activities in UK local elections in 2002 was by the widespread use of digital technologies. Computers, email and mobile phones were all intelligently used in order to organise and arrange flows of both information and people, as part of a concerted campaign to maintain a high public profile. Thus, many of those involved in the coordination of this campaign could be said to have had digital life-styles. Yet the same goods, services and activities that characterised such activity are shared by me, a left-wing academic who is openly antagonistic and hostile to such a political grouping. To what extent, then, do our digital life-styles coincide in any meaningful sense? The second contrast is with a group of people who certainly could be said to have exemplary digital life-styles. These people use the internet in order to share and disseminate a particular form of visual information. They maintain contact through the use of email correspondence and internet chat rooms; they regularly use digital cameras, scanners and other technologies in the production of particular images. These people are paedophiles. While they may share much in common amongst themselves, just what do they have in common with others who have digital life-styles? Little, apart from the use of particular technologies and services for particular ends. Thus, how socially significant is the identification of someone as having a 'digital' life-style? 


\section{Life-style as political and social containment}

There are those dissenting activities and beliefs that have their radical potential camouflaged and diluted by the charge of being 'alternative' life-styles. For example, to label a radical socialist with strong convictions about social change, who engages in political action, who adopts a morality and sensibility congruent with their politics and desire for social transformation, as pursuing an 'alternative' life-style is deeply insulting. It reduces political conviction to the same level as a life-style built around shopping for the paraphernalia of commodity culture.

As Marcuse argued, 'In exhibiting its contradictions as the token of its truth, this (cultural capitalist) universe of discourse closes itself against any other discourse which is not on its own terms' (Marcuse, 1964: 90). Lifestyle homogenises qualitative differences in this way. On the other hand, however, our radical might be considered as not having a life-style at all, the term being reserved for those engaging in what can be presented as more 'legitimate' activities. Hence the term can be used to signify social exclusion - usually of those who choose to oppose the social conditions that support life-style societies. Here we are dealing with a different kind of 'unhealthy' life-style, and with a different kind of injunction to 'improve' on it. But just what do such injunctions actually mean? Just what is to be 'improved': one's morality, ethical standpoint, political convictions, social sensibilities? Well, no; it usually means that one 'improves' one's spending power and ability to consume commodities, and/or 'improves' one's cultural sensibilities and social status by becoming more discriminating about what is consumed or displayed, having enhanced one's taste concerning the latest commodities to be consumed.Taste, here, is arbitrated by the promotional industries of capitalism and the life-style media.

The term 'life-style' suggests, it seems to me, that it is a mode of living that rests upon making choices between predetermined options - life-style choices, rather than life choices (Fromm, 1976). ${ }^{4}$ Critical social theorists should abandon the use of the term, or at least use it pejoratively, so that its origins and linguistic, conceptual and practical effects are critically highlighted. This is a Canute-like call: an ineffectual howl, probably, at a tide that cannot be turned back. Perhaps one day it will be common to see on

\footnotetext{
${ }^{4}$ I believe that this calls into question Giddens's often-referenced distinction between life-style politics and 'emancipatory' politics (Giddens, 1991).
} 
people's gravestone epitaphs, instead of a remembrance of their full, interesting, loving or happy lives, a reference to the fact that they 'had a good life-style'.

\section{References}

Baumann, Z. (1998) Work, Consumerism and the New Poor (Open University Press)

Bowring, F. (1999) 'Job scarcity: The perverted form of a potential blessing', in Sociology, vol. 31, no. 1.

Campbell, C. (1995) 'The sociology of consumption', in D. Miller (ed.) Acknowledging Consumption (Routledge) London.

Chaney, D. (1996) Lifestyles (Routledge) London.

Fromm, E. (1976) To Have or to Be? (Harper and Row) New York.

Giddens, A. (1991) Modernity and Self-Identity: Self and Society in the Late Modern Age (Polity Press) Cambridge.

Greenhalgh, P. (1997) 'The progress of Captain Ludd', in P. Dormer (ed.)

The Culture of Craft (Manchester University Press).

Lodziak, C. (2000) 'On explaining consumption' in Capital \& Class no. 72, Environmental Politics: Analyses and Alternatives Special Issue.

Lodziak, C. (2002) The Myth of Consumerism (Pluto Press) London. Marcuse, H. (1964) One-Dimensional Man (Beacon Press) Boston.

Warde, A. (1994) 'Consumption, identity-formation and uncertainty', in Sociology, vol. 28 , no. 4. 